\title{
Simple LC Isocratic Methods Development, Validation, and Application in the Analysis of Poor Quality Antimalarial Medicines
}

\author{
Védaste Habyalimana ${ }^{1,2}$, Jérémie Kindenge Mbinze ${ }^{3}$, Achille Loconon Yemoa ${ }^{4}$, \\ Justin-Léonard Kadima Ntokamunda ${ }^{5}$, Philippe Hubert ${ }^{1}$, \\ Roland Marini Djang'eing'a ${ }^{1}$
}

\author{
${ }^{1}$ Laboratory of Pharmaceutical Analytical Chemistry, CIRM, University of Liège (ULg), Liège, Belgium \\ ${ }^{2}$ Rwanda Biomedical Center/Medical Procurement and Production Division, Kigali, Rwanda \\ ${ }^{3}$ Faculty of Pharmaceutical Sciences, University of Kinshasa, Kinshasa XI, Democratic Republic of Congo \\ ${ }^{4}$ Faculty of Health Sciences, School of Pharmacy, University of Abomey Calavi, Cotonou, Benin \\ ${ }^{5}$ School of Medicine and Pharmacy, University of Rwanda, Butare, Rwanda \\ Email: rmarini@ulg.ac.be
}

How to cite this paper: Habyalimana, V., Mbinze, J.K., Yemoa, A.L., Ntokamunda, J.-L.K., Hubert, P. and Djang'eing'a, R.M. (2017) Simple LC Isocratic Methods Development, Validation, and Application in the Analysis of Poor Quality Antimalarial Medicines. American Journal of Analytical Chemistry, 8, 582-603.

https://doi.org/10.4236/ajac.2017.89042

Received: July 18, 2017

Accepted: September 16, 2017

Published: September 19, 2017

Copyright (c) 2017 by authors and Scientific Research Publishing Inc. This work is licensed under the Creative Commons Attribution International License (CC BY 4.0).

http://creativecommons.org/licenses/by/4.0/

\section{(c) (i) Open Access}

\begin{abstract}
Liquid chromatographic methods in isocratic mode for the analysis of poor quality medicines are privileged due to their simplicity and facility in methods development. They are generally fast; do not need to be re-equilibrated between sample injections; have larger flexibility with acceptable changes on different column dimensions; and are applicable to LC systems equipped with simple or high developed pumps. In this study, we focused on developing simple isocratic methods using classical mobile phase composed by methanol and ammonium formate buffer for the analysis of most common antimalarial medicines marketed in malaria endemic countries and susceptible of being counterfeit/falsified, substandard and degraded. The selected medicines were quinine and related cinchona alkaloids in tablets and injectable forms; artemether/lumefantrine tablets; and artemisinin compounds (arteether, artemether, and artesunate) in injectable forms. The current methods were developed thanks to simple methodological approach consisting in sequential isocratic runs through adjustment or adaptation of existing methods to obtain optimal analytical conditions without complex design of experiments that might be long and costly. Then, the new methods presented shorter analysis time; allowed increase of sample analysis throughput; and obviously consumed little mobile phase solvents on classical analytical columns: 50 - 250 $\mathrm{mm}$ of length (L), $4.6 \mathrm{~mm}$ of internal diameter (I.D.), and $3.5-5.0 \mu \mathrm{m}$ of particle size (dp).
\end{abstract}




\section{Keywords}

Antimalarial Medicines, Liquid Chromatography, Isocratic Mode, Validation, Poor Quality Medicines

\section{Introduction}

Malaria is a life-threatening disease caused by Plasmodium parasites transmitted to people through the bites of infected female Anopheles mosquitoes (called malaria vectors). It is usually found in tropical and subtropical climates where the parasites live [1] [2]. According to the latest estimates of the World Health Organization (WHO), released in end of 2016, there were 212 million cases of malaria in 2015 and 429,000 deaths. The WHO African Region is the most affected by that disease and its consequences [1]. Thus far, the prevention of malaria involves among others the use of "insecticide-treated mosquito nets" and "indoor residual spraying" as effective vector control mechanisms, and the use of "antimalarial medicines" in disease treatment or chemoprophylaxis. Concerning medicines, they should always meet their quality specifications in order to give guarantee on their safety and efficacy during their shelf lives. Otherwise, any failure to the required quality standards may lead to serious public health concerns such as failure in disease treatment, development of drug resistance, increase of morbidity and mortality, etc.

Indeed, poor quality medicines constitute a harmful threat to the public health worldwide, particularly in under-resourced countries [3] [4] [5]. Newton et al. [3] distinguished three categories of poor quality medicines: (i) Counterfeit/falsified medicines which are illicit products maliciously produced and distributed; (ii) Substandard also called out-of-specification "OOS" products which are genuine products generally produced in poor manufacturing conditions; and (iii) Degraded medicines which are products improperly stored, and spoiled. Hence, there is need to develop fast, effective, simple and transferable analytical methods to drug quality control laboratories in developing countries, and therefore reinforce their capacity in detecting and fighting against the spread of those harmful products.

In this context, we have developed simple isocratic methods for the analysis of curative antimalarial medicines most used in Rwanda i.e. artemether/lumefantrine, artesunate, and quinine with related other compounds that should be associated with them in case of counterfeiting, substandard, or degradation. This is the case for example of quinine and related cinchona alkaloids such as cinchonine, cinchonidine, quinidine, and dihydroquinine, together with resorcinol most found in quinine resorcin formulations, etc. Moreover, we added arteether to the group of artemisinin derivatives that should be easily interchanged with artemether and artesunate due to their closer chemical structure similarity (see Figure 1).

The technique of Liquid Chromatography (LC) coupled with UV detector or 


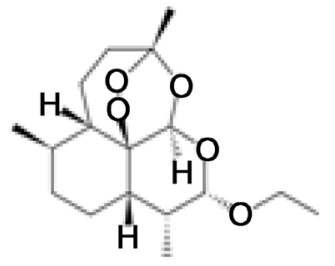

Arteether<smiles>C=C[C@H]1CC2CCN1CC2[C@H](O)c1ccnc2ccccc12</smiles>

Cinchonidine

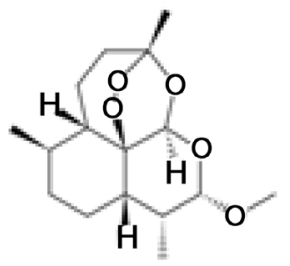

Artemether<smiles>C[C@H]1CC[C@H]2[C@@H](C)C(OC(=O)CCC(=O)O)OC34O[C@](C)(CC[C@@H]13)O[C@@]24O</smiles>

Artesunate<smiles>CCCCN(CCCC)CC(O)c1cc(Cl)cc2c1-c1ccc(Cl)cc1C2=Cc1ccc(Cl)cc1</smiles>

Lumefantrine

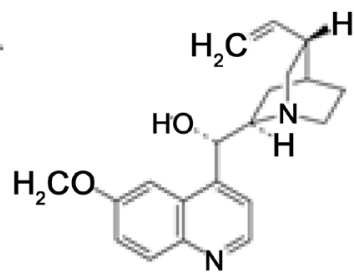

Quinidine<smiles>CCCCOc1cc(C(=O)NCCN(CC)CC)c2ccccc2n1</smiles>

Cinchonine<smiles>CCC1CN2CCC1CC2[C@H](O)c1ccnc2ccc(OC)cc12</smiles>

Dihydroquinine

Figure 1. Molecular structures of the studied analytes.

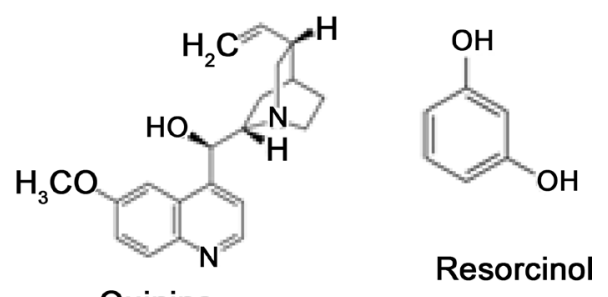

Quinine

DAD was selected as gold standard for chemical separation, quantification and identification of simple and complex samples. This technique is highly used in pharmaceutical analysis, very sensitive and accurate; it gives results in relatively good-time, generally within approximately 10 and 15 minutes for isocratic methods, and within less than 60 minutes for gradient methods; and has a great capacity of automation [5] [6].

The targeted methods were privileged for their simplicity, shorter analysis time, and higher analysis sample throughput; they were developed thanks to the adjustment (fine-tuning) or adaptation of other existing methods in fewer experimental runs without passing through design of experiments that are information fullness however with high cost and relatively long time consuming.

Then, after optimizing the new methods, they must be validated according to the International Conference on Harmonization "ICH-Q2(R1)" guidelines [7], and we used the total error strategy based on random and systematic errors corresponding to the precision + trueness, and using accuracy profiles as decision tool on the fitness of the methods for their intended use within given acceptable limits [8] [9] [10] [11].

Finally, in the frame of reducing the analysis time, we transferred the methods from long to shorter analytical columns in the classical range of $250 \mathrm{~mm}$ and 50 $\mathrm{mm}$ of length (L) $\times 4.6 \mathrm{~mm}$ of internal diameter (ID), and 5.0 to $3.5 \mu \mathrm{m}$ of the particle size (dp) before use in routine analysis of different medicines especially when detecting counterfeit formulations. 


\section{Materials and Methods}

\subsection{Materials}

Arteether (100\%), Artemether (100\%), Artesunate (>97\%), and Lumefantrine (100\%) were purchased from Sensa Pharm (Lanchester, UK), and quinine sulfate (99.0\%) from Fagron N.V. (Waregem, Belgium), quinine dihydrochloride (100.8\%) from Molekula Limited (Dorset, UK), Hydrochloric acid (37\%) and ammonium formate (98.1\%) from VWR International BVBA (Leuven, Belgium), Methanol LC grade from Avantor Performance Materials B.V. (Deventer, The Netherlands), the Ultrapure Water was produced with a Milli-Q Plus 185 water purification system (Millipore, Billerica, MA, USA), and various samples of quinine tablets $(300 \mathrm{mg})$, quinine for injection $(300 \mathrm{mg} / \mathrm{mL}$ and $600 \mathrm{mg} / \mathrm{mL}$ ) as labeled on the primary packaging, artemether/lumefantrine tablets $(20 \mathrm{mg}$ / $120 \mathrm{mg}$ and $80 \mathrm{mg} / 480 \mathrm{mg}$ ), and artesunate powder for injection $(60 \mathrm{mg}$ ) were randomly collected from Rwanda, Democratic Republic of Congo, and Benin.

\subsection{Methods Development Strategy and Validation}

Methods in isocratic mode were developed by simple systematic approach, and by adaptation or adjustment of other methods on similar compounds. These methodologies have an advantage of reducing the number of experiments to be carried out without going through complex design of experiments (DoEs). The strategy of simple systematic approach was based on sequential isocratic runs and optimization of the most promising results, while the methods adaptation or adjustment was based on other methods found in literature (scientific publications) on the same analytes, and tested with adequate adaptations or adjustments to have the desired chromatographic conditions using our preferred mobile phase composed by methanol and ammonium formate buffer.

\subsection{Instrumental and Software}

\subsubsection{LC Equipment}

The methods were developed in Belgium on a Waters 2695 Alliance HPLC Separation Module coupled to Waters 2996 photodiode array (PDA) detector from Waters Corporation (Milford, MA, USA) piloted with Empower 2.0 software (Waters Corporation).

Different chromatographic columns packed with C18 or C8 stationary phases, in different dimensions ( $\mathrm{L}: 50 \mathrm{~mm}$ to $250 \mathrm{~mm}$, ID: $4.6 \mathrm{~mm}$; dp: $3.5 \mu \mathrm{m}$ and 5 $\mu \mathrm{m})$ were used during the methods development and geometric transfer as described in the experimental part.

\subsubsection{Software}

Empower 2.0 software (Waters Corporation, MA, USA) for Windows was used to control the Waters Alliance HPLC system, to record the signals from the detector and interpret the generated chromatograms. Then, different optimum

levels for geometric transfer from columns to others were calculated using 
HPLC Calculator v3.0 developed by Guillarme et al. [12], and the accuracy profiles as well as the statistical calculations including the validation results and uncertainty estimates were obtained thanks to e-noval ${ }^{\circledR}$ V3.0 software (Arlenda, Belgium).

\subsection{Preparation of Sample Solutions}

\subsubsection{Sample Solutions for Method Development for the Analysis of Arteether, Artemether, Artesunate and Quinine in Different Injectable Formulations}

In the first step, approximately $10.0 \mathrm{mg}$ of quinine base from quinine dihydrochloride chemical reference substance (CRS) were dissolved with methanol in $100.0 \mathrm{~mL}$ volumetric flask; and in the second step, this solution was used to dissolve and dilute approximately $10.0 \mathrm{mg}$ of each of the arteether, artemether and artesunate reference substances weighed in a $2.0 \mathrm{~mL}$ volumetric flask. This was the final working solution annotated "Solution $Q 3 A$ " to be injected in the chromatographic system. It contained approx. $100 \mu \mathrm{g} \mathrm{mL} \mathrm{L}^{-1}$ of quinine, and 5000 $\mu \mathrm{g} \mathrm{mL} \mathrm{L}^{-1}$ of the three artemisinin derivate compounds.

\subsubsection{Sample Solutions for Method Adaptation for the Analysis of Quinine, Resorcinol, Quinidine, Dihydroquinine and Other Cinchona Alkaloids in Tablets and Injectable Formulations}

The working sample solutions were prepared from two real medicines containing the studied analytes (i.e. quinine, dihydroquinine, quinidine, cinchonine, cinchonidine, and resorcinol) manufactured by Sanofi-Winthrop Pharma (Senegal) and Wintac Ltd. (India).

Each sample solution was diluted with purified water to have a final working solution containing approximately $100 \mu \mathrm{g} \mathrm{mL}^{-1}$ of quinine alkaloid which is the main active ingredient, and the concentrations of other cinchona alkaloids together with resorcinol were subsequently reduced according to the product formulation as stated on the labeled composition. For example, one sample of ampoule $4 \mathrm{~mL}$ was stated to contain per mL: $96.10 \mathrm{mg}$ of quinine resorcinol dihydrochloride, $2.55 \mathrm{mg}$ of quinidine resorcinol dihydrochloride, $0.68 \mathrm{mg}$ of cinchonine resorcinol dihydrochloride, $0.67 \mathrm{mg}$ of cinchonidine resorcinol dihydrochloride, and water for injection BP q.s. Then, to have final working solutions containing approx. $100 \mu \mathrm{g} \mathrm{mL}^{-1}$ of quinine resorcinol dihydrochloride, 520 $\mu \mathrm{L}$ of quinine resorcine injection sample were diluted in $500 \mathrm{~mL}$ volumetric flasks before they were injected in the chromatographic system for analysis. Note that the content of resorcinol was not mentioned on both samples, but the product was well identified as shown later in results. Then, to identify all six analytes, we injected separately in the LC system single solutions of quinine reference substance $\left(100 \mu \mathrm{g} \mathrm{mL} \mathrm{m}^{-1}\right.$ in purified water) containing dihydroquinine $(<10 \%)$, cinchonine CRS (50 $\mu \mathrm{g} \mathrm{mL}^{-1}$ in purified water), cinchonidine CRS (50 $\mu \mathrm{g} \mathrm{mL} \mathrm{m}^{-1}$ in purified water), quinidine CRS $\left(50 \mu \mathrm{g} \mathrm{m}^{-1}\right.$ in purified water), and resorcinol CRS ( $50 \mu \mathrm{g} \mathrm{mL}^{-1}$ in purified water too). 


\subsubsection{Sample Solutions for Method Adjustment for the Analysis of Artemether/Lumefantrine in Tablet Formulations}

Reference to the USP, International and European pharmacopoeias allowable adjustments in chromatographic systems [13] [14] [15], our previously validated method for the analysis of artemether/lumefantrine in tablets forms [16] was adjusted in order to reduce the analysis time and increase the sample analysis throughput. The following solutions were prepared:

\section{Standard solutions.}

Dissolve accurately weighed quantities of artemether and lumefantrine reference substances in appropriate volumetric flask with acidified methanol by phosphoric acid (0.2\% phosphoric acid in methanol, w/v) to obtain 200 and $1200 \mu \mathrm{g} \mathrm{mL} \mathrm{L}^{-1}$ of both analytes respectively. Prepare two independent standard solutions for system suitability testing and analysis.

\section{Sample solutions:}

Different samples randomly collected using blind sampling techniques from Rwanda ( $n=13)$, D.R. Congo ( $n=9)$, and Benin ( $n=1$ suspected counterfeit) were prepared for analysis in the frame of quality assessment of artemisinin-based combination therapy (ACT) medicines marketed in the three countries.

The sample solutions were prepared by weighing and powdering 20 tablets; and transferring a quantity of each sample powder containing approximately 20 $\mathrm{mg}$ of artemether and $120 \mathrm{mg}$ of lumefantrine accurately weighed in $100.0 \mathrm{~mL}$ volumetric flask, and dissolving the sample with the acidified methanolic solution (phosphoric acid $0.2 \%, \mathrm{w} / \mathrm{v}$ ) used in the preparation of artemether/lumefantrine standard solutions by mechanical shaking on vortex during 1 minute, and dilution to volume with the same solvent to obtain approx. 200 and $1200 \mu \mathrm{g} \mathrm{m}^{-1}$ of both analytes respectively. Prepare three independent sample solutions per batch, and filter each solution through $0.45 \mu \mathrm{m}$ filter before they are injected in the chromatographic system.

\subsubsection{Sample Solutions for Method Validation and Routine Analysis for Artesunate Powder for Injection}

\section{a) Sample solutions for method validation}

They consisted of three concentration levels for calibration standards (CS), and five concentration levels for validation standards (VS). The required solutions were prepared as described in section 3.2.

\section{b) Sample solutions for routine analysis}

The samples of artesunate powder for injection were prepared by dissolving with methanol LC grade approximately $10.0 \mathrm{mg}$ of the sample in $2.0 \mathrm{~mL}$ volumetric flasks and completing to volume with the same solvent to obtain around $5000 \mu \mathrm{g} \mathrm{mL}^{-1}$ final solutions against artesunate reference substance prepared at the same concentration level with the same solvent. Three independent sample solutions were prepared, and two independent reference solutions for system suitability testing and sample analysis. 


\section{Experimentation}

\subsection{Simple Isocratic Methods Development by Adaptation or Adjustment and Sequential Isocratic Runs with Fine-Tuning}

Simple isocratic methods for the analysis of (i) quinine and artemisinin derivatives (arteether, artemether, and artesunate), (ii) quinine resorcin and major cinchona alkaloids (cinchonine, cinchonidine, quinidine, and dihydroquinine), and (iii) artemether/lumefantrine in different pharmaceutical forms were developed through sequential isocratic runs with optimization (fine-tuning), and by simple adaptation or adjustment of other methods in order to reduce the analysis time, improve the sample treatments conditions, and use of our preferred mobile phase composed by methanol and ammonium formate buffer which is not expensive and that can be transferred to LC/MS for advanced analysis whenever needed for the identification of unknown compounds. Moreover, isocratic methods have an advantage of flexibility to tolerable changes with column dimensions, flow rate of the mobile phase, organic modifier proportion, etc. that can be done without need of the methods revalidation [13] [14] [15].

\subsubsection{Development of a Generic Method for the Analysis of Quinine,} Arteether, Artemether and Artesunate in Injectable Formulations

The development of a generic isocratic method for the analysis of quinine, arteether, artemether and artesunate was done through a simplified systematic approach based on sequential isocratic runs with optimization (fine-tuning) described in Table 1, using classical analytical columns and mobile phase composed by methanol and ammonium formate buffer.

The first three experiments helped to know the trend of peak separation of the four analytes either at higher or lower proportion of the organic modifier, and therefore have an idea on which parameter to make changes in the optimization phase. For example, if the best separation of the analytes is at the lower level of methanol (i.e. at Test 1: 25/75\% MeOH/Buffer, v/v ), one can plan for two additional tests at $25 \% \pm 10 \%$ of methanol (i.e. Test $4: 15 / 85 \%$ and Test $5: 35 / 65 \%$

Table 1. Simplified sequential isocratic experiments.

\begin{tabular}{|c|c|c|c|c|}
\hline \multirow{2}{*}{ Factor } & \multicolumn{4}{|r|}{ Experiments } \\
\hline & Test (1) & Test (2) & Test (3) & Optimization ( \pm 5 tests) \\
\hline Mobile phase: & $<50 \%$ & $50: 50 \%$ & $>50 \%$ & \\
\hline Methanol & $25 \%$ & $50 \%$ & $75 \%$ & About five more tests are added: For \\
\hline $\mathrm{NH}_{4}$ formate buffer ${ }^{(*)}$ & $75 \%$ & $50 \%$ & $25 \%$ & 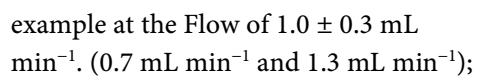 \\
\hline Flow rate $\left(\mathrm{mL} \mathrm{min}{ }^{-1}\right)$ & 1.0 & 1.0 & 1.0 & $\begin{array}{l}25 \text { or } 75 \pm 10 \%, \mathrm{v} / \mathrm{v} \text { of organic modifier } \\
(15: 85 \% \text {, or } 35: 65 \% ; 65: 35 \% \text { or } 85: 15 \%)\end{array}$ \\
\hline Column temperature $\left({ }^{\circ} \mathrm{C}\right)$ & 25 & 25 & 25 & $\mathrm{v} / \mathrm{v}$, column dimensions, or column tem- \\
\hline Injection volume $(\mu \mathrm{L})$ & 10 & 10 & 10 & perature adaptations, etc. \\
\hline Detection wavelength (nm) & 210 & 210 & 210 & \\
\hline
\end{tabular}

${ }^{(*)}$ : The aqueous mobile phase is $10 \mathrm{mM}$ ammonium formate $\mathrm{pH} 2.8$. 
$\mathrm{MeOH} / \mathrm{Buffer}, \mathrm{v} / \mathrm{v}$ ), and then continue the adjustment of the method with the

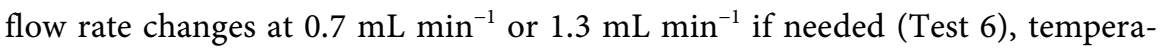
ture changes at $35^{\circ} \mathrm{C}$ (Test 7), or columns dimensions (Test 8: $\mathrm{L}=50-250 \mathrm{~mm}$; ID: $4.6 \mathrm{~mm}$; dp: 3.5 or $5 \mu \mathrm{m}$ ) in order to have the desired chromatographic separation within $\leq 10$ minutes of run time generally preferred for isocratic methods.

\subsubsection{Development of Isocratic Method for the Analysis of Quinine, Resorcinol, Dihydroquinine and Major Cinchona Alkaloids}

The analysis of quinine in different pharmaceutical forms is generally done with other cinchona alkaloids especially dihydroquinine that should not be more than $10 \%$ of content, cinchonidine not more than $5 \%$, and any other related substance such as cinchonine, quinidine, etc. at not more than $2.5 \%$ calculated by the area percentage method to quinine peak area [17].

Reference to other existing methods covering almost the same analytes [18] [19], we optimized a rapid isocratic method for the analysis of quinine, resorcinol, cinchonine, cinchonidine, quinidine, and dihydroquinine by adapting these methods to our analytes and changing the earlier mobile phase to methanol and ammonium formate buffer. Resorcinol was added to the list of the studied analytes, as being one of the key ingredients in quinine resorcin injection solutions widely used in different malaria endemic countries.

The method was optimized on a Zorbax SB-C8 (dp $3.5 \mu \mathrm{m})$ column, (150 mm $\times 4.6 \mathrm{~mm} \mathrm{ID}$ ) maintained at $35^{\circ} \mathrm{C}$, applying as mobile phase an isocratic mixture of methanol and $10 \mathrm{mM}$ ammonium formate buffer (adjusted to $\mathrm{pH} 2.8$ with formic acid or $6 \mathrm{~N}$ hydrochloric acid) $(40: 60, \mathrm{v} / \mathrm{v})$ for the analysis of quinine tablets containing generally quinine sulfate, dihydroquinine, and cinchonidine; and $(30: 70, v / v)$ for the analysis of quinine resorcin injection containing the six analytes (quinine, resorcinol, dihydroquinine, cinchonine, cinchonidine, and

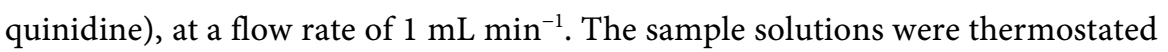
at $15^{\circ} \mathrm{C}$, introduced in the separation system at $10 \mu \mathrm{L}$ injection volumes, and monitored at $230 \mathrm{~nm}$.

\subsubsection{Adjustment of the Method for Analysis of Artemether/Lumefantrine in Tablet Formulations}

Our former analytical method for the analysis of artemether/lumefantrine in tablet formulations [16] was readjusted to improve the analysis time (run time), and sample treatment by increasing the capacity of methanol in dissolving lumefantrine. Hence, to improve the analysis time, we slightly increased the proportion of methanol in the mobile phase and the run time reduced; then, to increase the capacity of methanol in dissolving lumefantrine, we slightly increased the acidity power by using methanol acidified with phosphoric acid $0.2 \%(\mathrm{w} / \mathrm{v})$ instead of $0.1 \%(\mathrm{w} / \mathrm{v})$ previously used.

The method was adjusted on a Zorbax $80 \AA$ Extend-C18, $100 \mathrm{~mm} \times 4.6 \mathrm{~mm}$ (ID), (dp: $3.5 \mu \mathrm{m})$ chromatographic column at a flow rate of $0.7 \mathrm{~mL} \mathrm{~min}{ }^{-1}$ of methanol and $10 \mathrm{mM}$ ammonium formate buffer $\mathrm{pH} 2.8(85: 15 \%$, v/v) maintained 
at $25^{\circ} \mathrm{C}$, injecting $6 \mu \mathrm{L}$ of the sample and reference solutions, and recording the chromatographic data at $210 \mathrm{~nm}$. The dissolution of lumefantrine was improved by slight increases of the phosphoric acid in methanol from the original content of $0.1 \%$ to $0.2 \%(\mathrm{w} / \mathrm{v})$ that is enough to dissolve the targeted analyte by hand shaking or vortex easily.

\subsection{Validation of the Method for Analysis of Artesunate Powder for Injection}

The generic isocratic method for the analysis of quinine and artemisinin derivatives was validated for specific analysis of artesunate powder for injection. The calibration and validation standard solutions were prepared by dissolving artesunate CRS in methanol in order to have the following solutions.

\section{Calibration standards}

Level 1 (60\%): $3000 \mu \mathrm{g} \mathrm{mL}^{-1}$ of artesunate (approx. $15.0 \mathrm{mg}$ in $5.0 \mathrm{~mL}$ vol. flask); Level 3 (100\%): $5000 \mu \mathrm{g} \mathrm{mL}^{-1}$ of artesunate (approx. $10.0 \mathrm{mg}$ in $2.0 \mathrm{~mL}$ vol. flask); Level 5 (140\%): $7000 \mu \mathrm{g} \mathrm{mL} \mathrm{m}^{-1}$ of artesunate (approx. $14.0 \mathrm{mg}$ in $2.0 \mathrm{~mL}$ vol. flask).

\section{Validation standards}

The validation standards (VS) were prepared with artesunate CRS and methanol as solvent. There is no sample matrix as the studied product is a pure raw material without any excipient, and the concentration level is higher due to the weak absorption of the UV light by artesunate.

The VS were prepared to have five different concentration levels, three series per day, during three validation days.

Level 1 (60\%): $3000 \mu \mathrm{g} \mathrm{mL}^{-1}$ of artesunate (approx. $15.0 \mathrm{mg}$ in $5.0 \mathrm{~mL}$ vol. flask);

Level 2 (80\%): $4000 \mu \mathrm{g} \mathrm{mL}^{-1}$ of artesunate (approx. $20.0 \mathrm{mg}$ in $5.0 \mathrm{~mL}$ vol. flask);

Level 3 (100\%): $5000 \mu \mathrm{g} \mathrm{mL}^{-1}$ of artesunate (approx. $10.0 \mathrm{mg}$ in $2.0 \mathrm{~mL}$ vol. flask);

Level 4 (120\%): $6000 \mu \mathrm{g} \mathrm{mL}^{-1}$ of artesunate (approx. $12.0 \mathrm{mg}$ in $2.0 \mathrm{~mL}$ vol. flask);

Level 5 (140\%): $7000 \mu \mathrm{g} \mathrm{mL} \mathrm{L}^{-1}$ of artesunate (approx. $14.0 \mathrm{mg}$ in $2.0 \mathrm{~mL}$ vol. flask).

To sum up, three independent solutions $(\mathrm{n}=3)$ were prepared per each concentration level ( $c=3$ for CS, $c=5$ for VS), and all these preparations were repeated for three days corresponding to three series $(s=3)$. The method was validated on a C18, $150 \times 4.6 \mathrm{~mm}$, dp: $5 \mu \mathrm{m}$ column in order to allow covering the widest range of classical HPLC columns' sizes and allowable changes.

Then, for routine analyses, two independent reference solutions for system suitability testing and sample analysis were prepared at $5000 \mu \mathrm{g} \mathrm{mL}^{-1}$ i.e. Level 3 $(100 \%)$ against three independent sample solutions per batch was prepared at the same concentration level.

\subsection{Sampling and Application of the Methods on Real Samples}

Seventeen sampling sites mapped in Figure 2 were defined for collecting different antimalarial medicines found on the list of national essential medicines for Rwanda [20] [21] [22]. The targeted sampling points were hospitals and pharmacies in public and private sectors, and tentatively illicit vendors if available, located in strategic cities, suburbs, and Rwanda's borders. 
The sampling sites were selected on the basis of areas known to have intensive commercial activities, border areas with other countries (Burundi in South, Tanzania in East, Uganda in North, and D.R. Congo in West) where the risk of illegal trade of goods including medicines is relatively higher and therefore the possibility of entry of poor quality medicines especially counterfeit/falsified and substandard. All samples were selected randomly by considering batch numbers, manufacturers, strength, and dosage forms (tablets, capsules, injectables, etc.).

Moreover, other samples of antimalarial medicines were received from Kinshasa (university of Kinshasa, D.R. of Congo) and Cotonou (university of Abomey Calavi, Benin) in the frame of scientific collaboration including the University of Liège (Belgium) in the project of fighting against counterfeit medicines.

\section{Results and Discussions}

\subsection{Adaptation of the Method for the Analysis of Quinine, Resorcinol and Major Cinchona Alkaloids in Different Pharmaceutical Forms}

A simple isocratic method for the analysis of quinine, resorcinol, and major cinchona alkaloids in different pharmaceutical forms was optimized thanks to the adaptation of other methods. In fact, from literature search, we identified two interesting references [18] [19] from which we did necessary adaptations with our regular mobile phase composed by methanol and ammonium formate buffer. Hence, we decided to run some experiments around the practical conditions of the two reference methods as summarized in Table 1; and we got

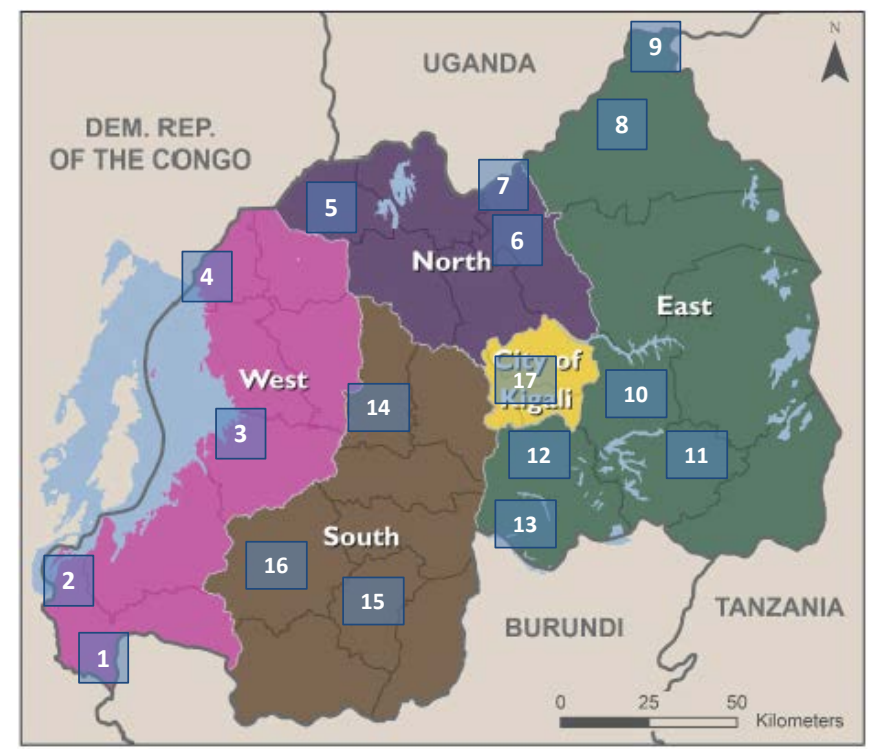

Figure 2. Strategic sampling sites on the map of Rwanda (Western Province: (1) Bugarama, (2) Kamembe, (3) Karongi/Kibuye, (4) Rubavu/Gisenyi; Northern Province: (5) Musanze/Ruhengeri, (6) Gicumbi/Byumba, (7) Gatuna; Eastern Province: (8) Nyagatare, (9) Kagitumba, (10) Rwamagana, (11) Ngoma/Kibungo, (12) Nyamata/Bugesera, (13) Ruhuha/Ngenda; Southern Province: (14) Muhanga/Gitarama, (15) Huye/Butare, (16) Nyamagabe/Gikongoro; and Kigali City: (17) The Capital). 
satisfactory results at $10 \mathrm{mM}$ ammonium formate buffer $\mathrm{pH} 2.8$ and methanol $(60: 40, v / v)$ as illustrated in Figure 3 for the analysis of quinine, dihydroquinine and cinchonidine generally tested in quinine tablet forms [17]; and for the analysis of quinine, resorcinol, cinchonine, cinchonidine, quinidine, and dihydroquinine in injectable forms, the optimum proportions of mobile phase was found at 70:30, v/v for $10 \mathrm{mM}$ ammonium formate buffer $\mathrm{pH} 2.8$ and methanol, respectively. Figure 4 illustrates the case of simultaneous separation of the six analytes in quinine resorcin solutions.

This method was also geometrically transferred to shorter analytical columns in order to reduce the analysis time and therefore increase the sample analysis throughput as well as reducing the consumption of the mobile phase.

\subsection{Adjustment of the Method for the Analysis of Artemether/lumefantrine in Tablet Forms}

Our earlier developed method in isocratic mode for the analysis of artemether and lumefantrine in tablet forms [16] was adjusted by improving the dissolution capacity of methanol on lumefantrine and therefore allowing to speed up the process of sample preparation by acidifying methanol at $0.2 \% \mathrm{w} / \mathrm{v}$ with phosphoric acid. Indeed, lumefantrine is practically insoluble in water, soluble in dichloromethane and chloroform, and slightly soluble in methanol but we privileged to dissolve it with the acidified methanol to avoid the use of chloroform or dichloromethane which are very chromophorous and capable of giving an additional peak in the chromatogram that would compete with lumefantrine and therefore reduce the detection of artemether which does not absorb well the UV light.

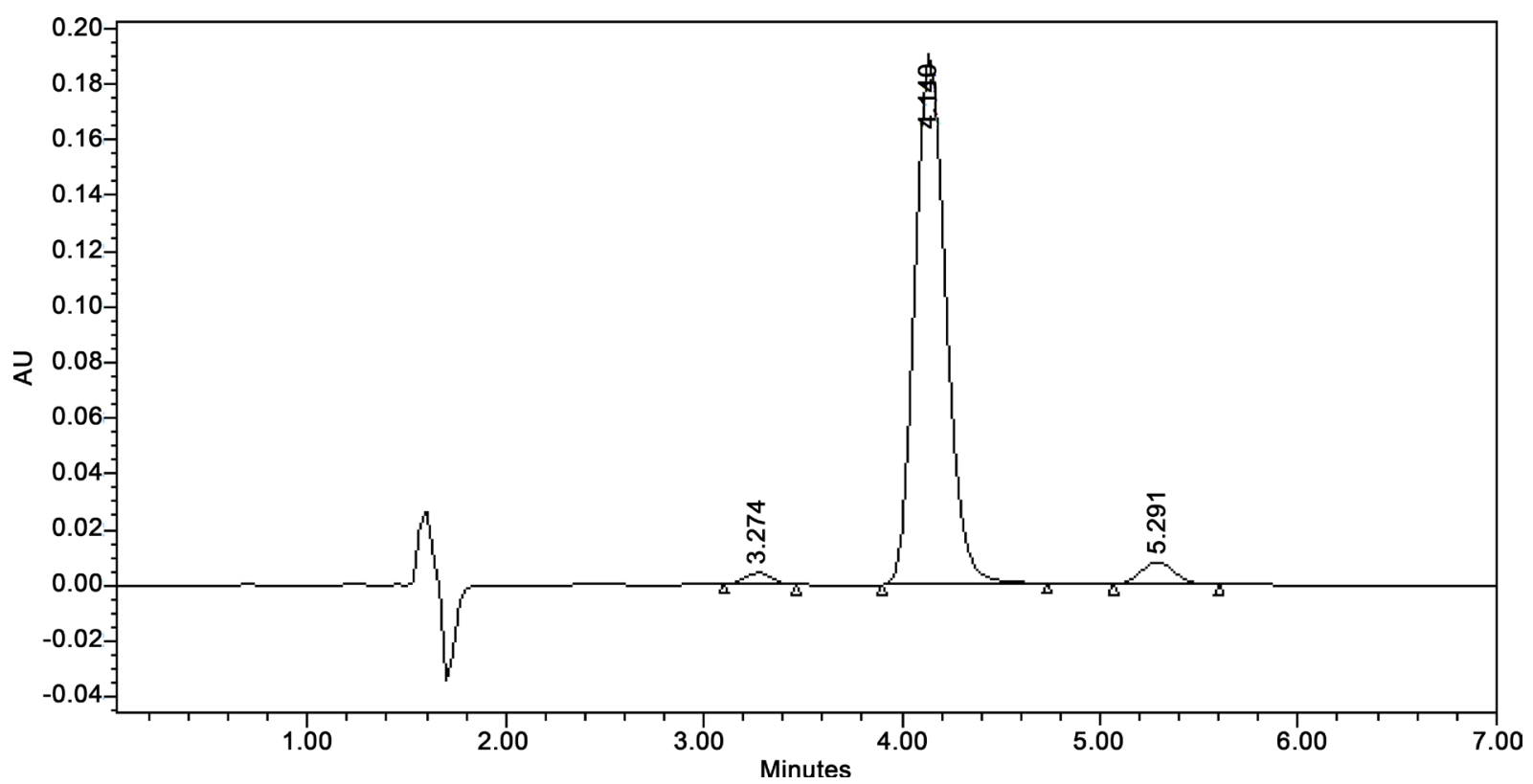

Figure 3. Isocratic method for the analysis of quinine and major cinchona alkaloids in tablet pharmaceutical forms. Experimental conditions: Column: Zorbax C8, $150 \times 4.6 \mathrm{~mm}$, dp: $5 \mu \mathrm{m}$; Flow: $1 \mathrm{~mL} \mathrm{~min}^{-1}$; $\mathrm{T}^{\circ}: 35^{\circ} \mathrm{C} ; \lambda=230 \mathrm{~nm}$; Isocratic elution with methanol and $10 \mathrm{mM}$ ammonium formate buffer $\mathrm{pH} 2.8(40: 60, \mathrm{v} / \mathrm{v})$. Elution order: Cinchonidine $(\approx 3.274 \mathrm{~min}$.), quinine ( $\approx 4.140 \mathrm{~min}$.), dihydroquinine ( $\approx 5.291 \mathrm{~min}$.). 

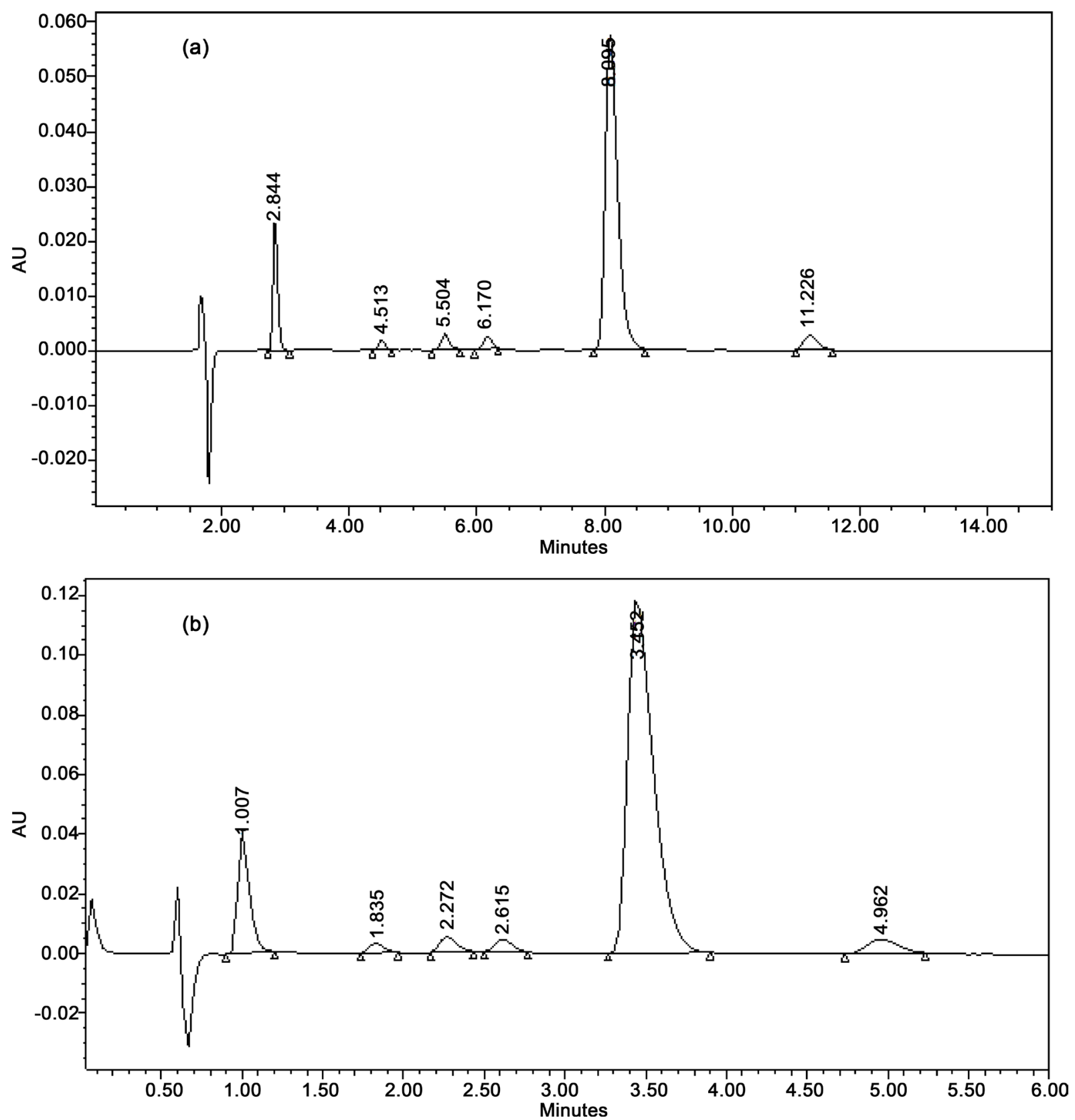

Figure 4. Isocratic method for the analysis of quinine resorcin and major cinchona alkaloids in injectable solutions. Experimental conditions: Column: Zorbax C8, $150 \times 4.6 \mathrm{~mm}$, dp: $5 \mu \mathrm{m}$ for chromatogram (a), and Zorbax C8, $50 \times 4.6 \mathrm{~mm}$, dp: $3.5 \mu \mathrm{m}$ for chromatogram (b); Flow: $1 \mathrm{~mL} \mathrm{~min}^{-1}$; $\mathrm{T}^{\circ}: 35^{\circ} \mathrm{C} ; \lambda=230 \mathrm{~nm}$; Isocratic elution with methanol and $10 \mathrm{mM}$ ammonium formate buffer $\mathrm{pH} 2.8(30: 70, \mathrm{v} / \mathrm{v})$. Elution order (identic to both chromatograms): i) Chromatogram (a): Resorcinol $(\approx 2.844 \mathrm{~min}$.$) , cinchonine (\approx 4.513 \mathrm{~min}$.$) , cinchonidine (\approx 5.504 \mathrm{~min}$.$) , quinidine (\approx 6.170 \mathrm{~min}$.$) , quinine (\approx 8.095$ min.), dihydroquinine ( $\approx 11.226 \mathrm{~min}$.); ii) Chromatogram (b): Resorcinol ( $\approx 1.007 \mathrm{~min}$.), cinchonine $(\approx 1.835 \mathrm{~min}$.), cinchonidine $(\approx 2.272 \mathrm{~min}$.), quinidine $(\approx 2.615 \mathrm{~min}$.), quinine $(\approx 3.452 \mathrm{~min}$.), dihydroquinine $(\approx 4.962 \mathrm{~min}$.).

Moreover, the amount of lumefantrine is six times the amount of artemether in different medicines, and this is another challenge during sample preparation as there is need of having an effective solvent for both analytes that cannot compromise the chromatographic results.

Hence, from the original method that had a run time of 16 minutes, we 
adapted the mobile phase proportions to $85: 15$, v/v of methanol and ammonium formate buffer $\mathrm{pH} 2.8$ respectively, $0.7 \mathrm{~mL} \mathrm{~min}{ }^{-1}$ of flow rate, and $25^{\circ} \mathrm{C}$ of column oven using a Zorbax-Extend C18, $80 \AA, 100 \times 4.6 \mathrm{~mm}(\mathrm{dp}: 3.5 \mu \mathrm{m})$ analytical column. This allowed to reduce the analysis time from 16 min to 6 minutes on a $100 \times 4.6 \mathrm{~mm}$ column as illustrated in Figure 5, and to 10 minutes on $150 \times$ $4.6 \mathrm{~mm}$ columns with the possibility to reduce the run time by changing the flow rate to $1.0 \mathrm{~mL} \mathrm{~min}^{-1}$ with the same mobile phase.

\subsection{Simple Development and Geometric Transfer of an Isocratic Method for the Analysis of Quinine, Arteether, Artemether and Artesunate in Injectable Forms}

A simple isocratic method for the analysis of quinine, arteether, artemether and artesunate was developed thanks to a simple systematic approach based on sequential isocratic runs described in Table 1 using octadecyl silane (ODS or C18) LC columns and the same mobile phase composed by methanol and ammonium formate buffer used in the previous methods development and optimization. In fact, we added quinine dihydrochloride to the three artemisinin compounds as another potential antimalarial medicine used in injectable forms to ensure that the method shall detect it in case of analyzing counterfeit medicines composed by one of the three artemisinin active ingredients.

Then, by following the planned systematic tests, we found better chromatographic results at higher proportions of the organic modifier, and we optimized the method at 90:10, v/v of methanol and $10 \mathrm{mM}$ ammonium formate buffer $\mathrm{pH}$

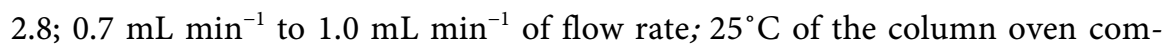
partment; and $210 \mathrm{~nm}$ of wavelength on a Zorbax Extend C18, $150 \times 4.6 \mathrm{~mm}$ (dp: $5 \mu \mathrm{m}$ ) column; and we transferred the method to XBridge Shield RP18, 100 $\times 4.6 \mathrm{~mm}(\mathrm{dp}: 3.5 \mu \mathrm{m})$, and Zorbax Extend C18, $50 \times 4.6 \mathrm{~mm}(\mathrm{dp}: 3.5 \mu \mathrm{m})$ columns to reduce the analysis time and mobile phase consumption, as well as allowing the increase of sample analysis throughput.

As illustrated in Figure 6, one can notice that the method has the ability of separating well the three artemisinin compounds, and that it can allow detecting any counterfeit of mixing them; but also the method was found capable of detecting quinine which is another potential injectable medicine from the three compounds.

\subsection{Methods Validation}

After methods optimization, it is necessary to demonstrate that the new methods are suit-for-purpose by providing accurate analytical results. In this regards, we have selected the method for analysis of artesunate powder for injection as a new antimalarial medicine in Rwanda aligned in the national list of essential medicines in 2015 [21] [22]. Moreover, this method can also help in detecting other arteminisin compounds such as arteether and artemether which are closely related to artesunate and which can be found in counterfeit or substandard artesunate medicines. Hence, the validation criteria as required by the International 

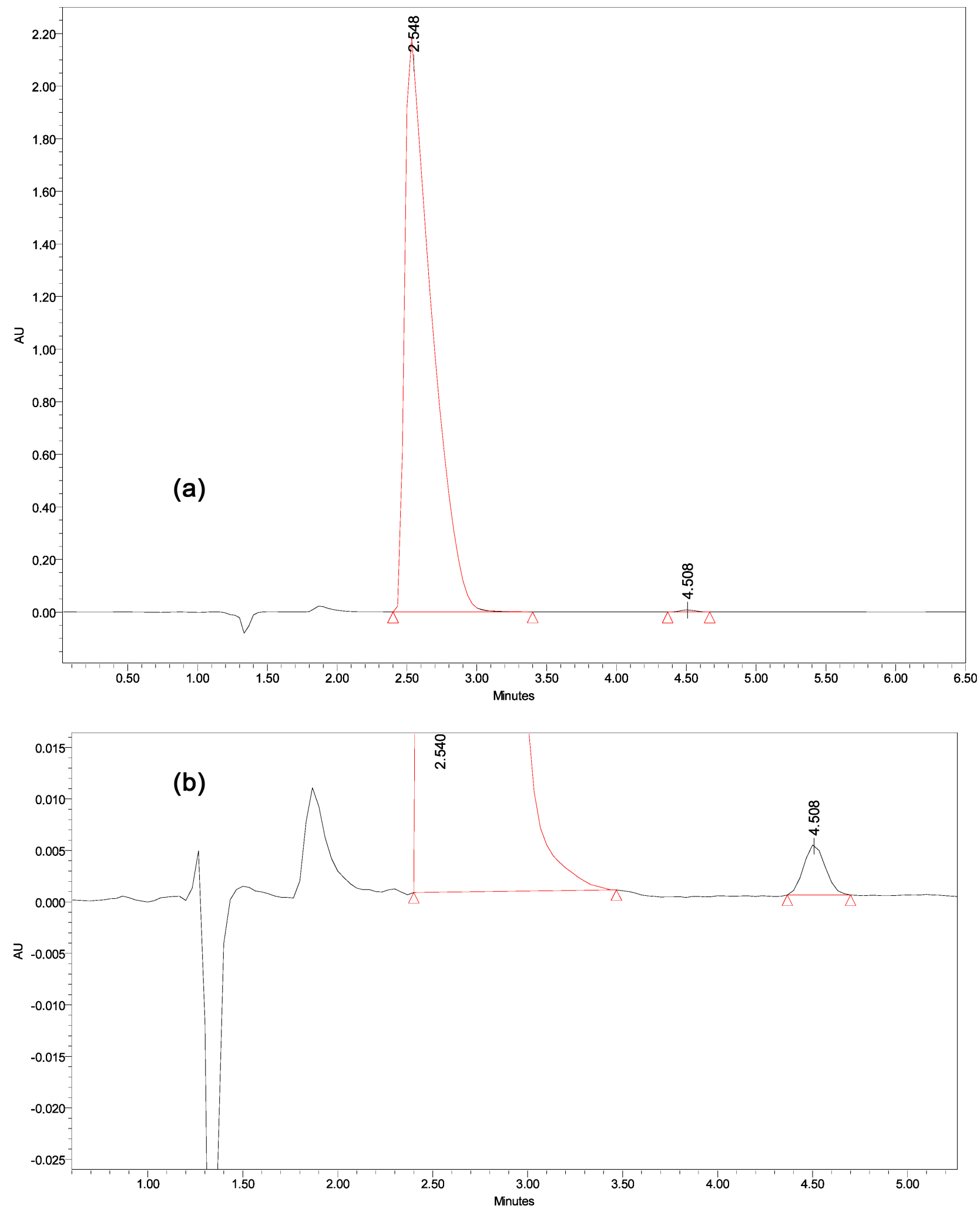

Figure 5. Readjusted isocratic method for the analysis of artemether-lumefantrine in tablet forms. Experimental conditions: Column: Zorbax-Extend C18, $80 \AA$, $100 \times 4.6 \mathrm{~mm}$, dp: $3.5 \mu \mathrm{m}$ (entire and zoomed chromatograms to visualize artemether); Flow: $0.7 \mathrm{~mL} \mathrm{~min}{ }^{-1} ; \mathrm{T}^{\circ}: 25^{\circ} \mathrm{C} ; \lambda=210 \mathrm{~nm}$; Isocratic elution with methanol and $10 \mathrm{mM}$ ammonium formate buffer $\mathrm{pH} \mathrm{2.8} \mathrm{(85:15,} \mathrm{v/v).}$ Elution order: Lumefantrine $(\approx 2.548 \mathrm{~min}$.) and artemether $(\approx 4.508 \mathrm{~min}$.) in Full chromatogram (a) and magnified chromatogram (b) for low abundant peak. 

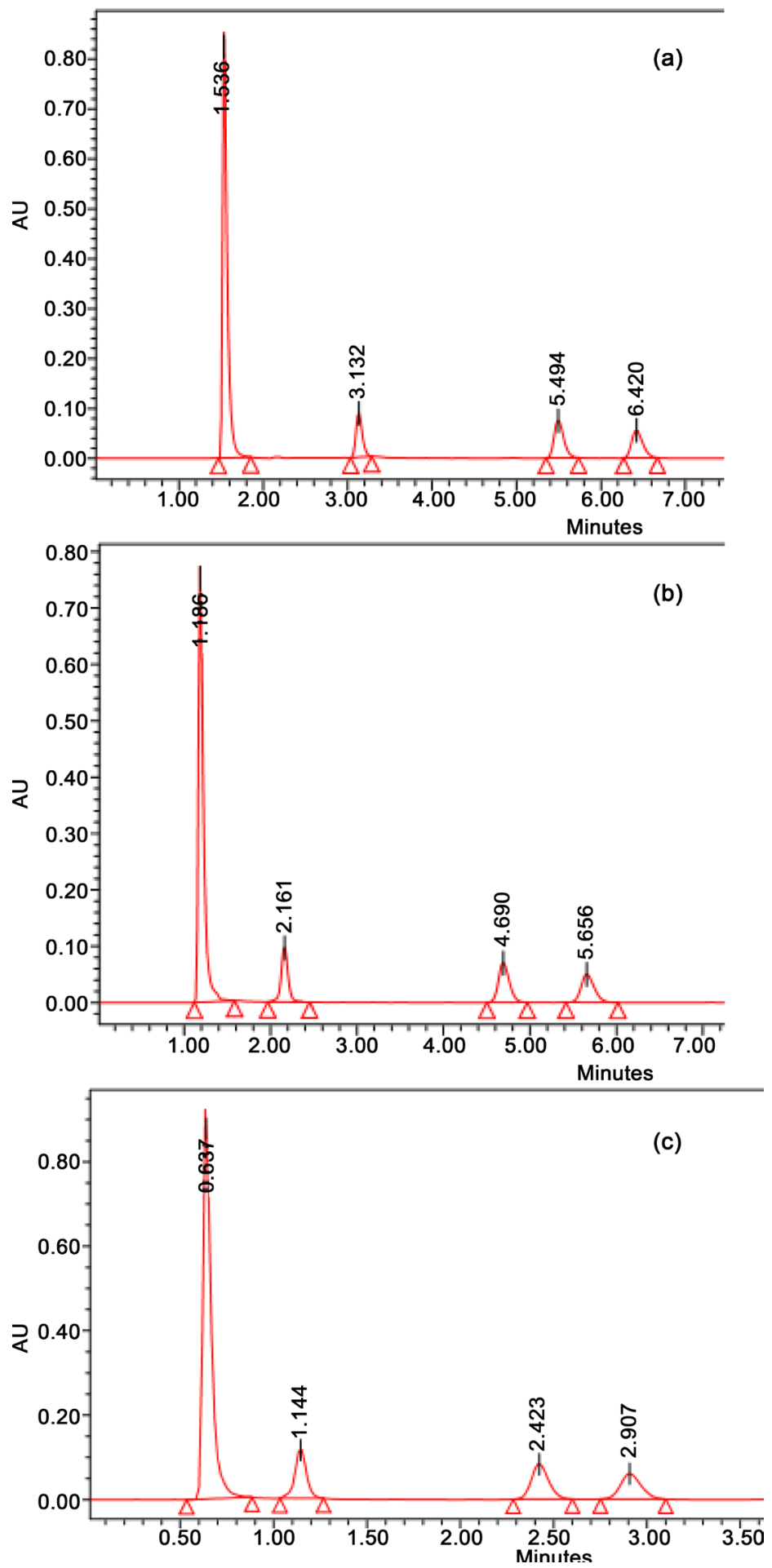

Figure 6. Isocratic method for the analysis of quinine, arteether, artemether and artesunate in injectable forms. Experimental conditions: Column: (a) Zorbax Extend C18, $150 \times 4.6 \mathrm{~mm}(\mathrm{dp}: 5 \mu \mathrm{m})$; (b) XBridge Shield RP18, $100 \times 4.6 \mathrm{~mm}(\mathrm{dp}: 3.5 \mu \mathrm{m})$; (c)

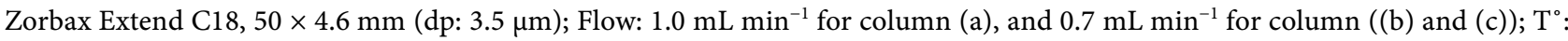
$25^{\circ} \mathrm{C} ; \lambda=210 \mathrm{~nm}$; Isocratic elution with methanol and $10 \mathrm{mM}$ ammonium formate buffer $\mathrm{pH} 2.8$ (90:10, v/v). Elution order: (identic in in the three chromatograms). i) Chromatogram (a): Quinine ( $\approx 1.536$ min.), artesunate $(\approx 3.132$ min.), artemether $(\approx 5.494 \mathrm{~min}$.$) , arteether ( \approx 6.420 \mathrm{~min}$.$) ; ii) Chromatogram (b): Quinine (\approx 1.186 \mathrm{~min}$.), artesunate $(\approx 2.161 \mathrm{~min}$.), artemether $(\approx 4.690 \mathrm{~min}$.), arteether $(\approx 5.656 \mathrm{~min}$.$) ; iii) Chromatogram (\mathrm{c})$ : Quinine $(\approx 0.637 \mathrm{~min}$.$) , artesunate (\approx 1.144 \mathrm{~min}$.), artemether $(\approx 2.423$ min. $)$, arteether $(\approx 2.907$ min. $)$. 
Conference on Harmonization (ICH) in its document Q2(R1) were considered namely: selectivity, trueness, precision (repeatability and intermediate precision), accuracy, linearity, limit of detection (LOD) / limit of quantitation (LOQ), and dosing range [7].

At first, we checked the selectivity of the method by checking whether there is no peak interference at the $t_{\mathrm{R}}$ of artesunate especially by other artemisinin compounds widely used in pharmaceutical formulations i.e. arteether and artemether, and this criteria was satisfactory as illustrated in Figure 7 since all peaks were well resolved.

At second, we applied the concept of total error strategy represented by accuracy profiles as decision tool on the fit-for-purpose of the method for its intended use [8] [9] [10] [11]. By using the data of CS, the linear regression model was constructed and allowed obtaining the calculated result from VS. Then, an accuracy profile for artesunate was drawn as can be seen in Figure 8 with the

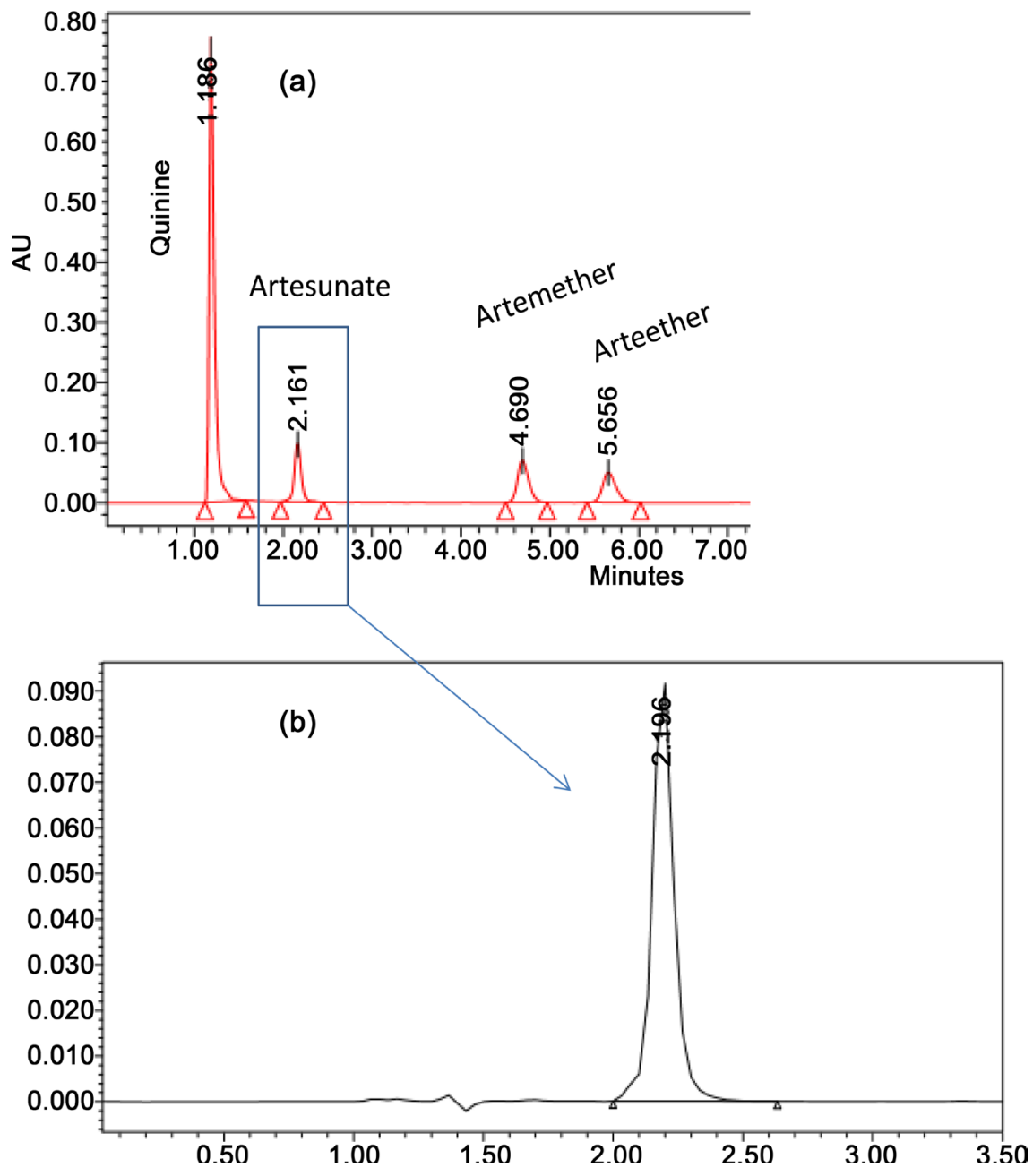

Figure 7. Chromatograms of artesunate with other compounds (a) and artesunate alone in a sample solution (b). Experimental conditions: Column: XBridge Shield RP18, $100 \times$ $4.6 \mathrm{~mm}(\mathrm{dp}: 3.5 \mu \mathrm{m})$; Flow: $0.7 \mathrm{~mL} \mathrm{~min}^{-1}$; $\mathrm{T}^{\circ}: 25^{\circ} \mathrm{C} ; \lambda=210 \mathrm{~nm}$; Isocratic elution with methanol and $10 \mathrm{mM}$ ammonium formate buffer $\mathrm{pH} 2.8(90: 10, \mathrm{v} / \mathrm{v})$. 


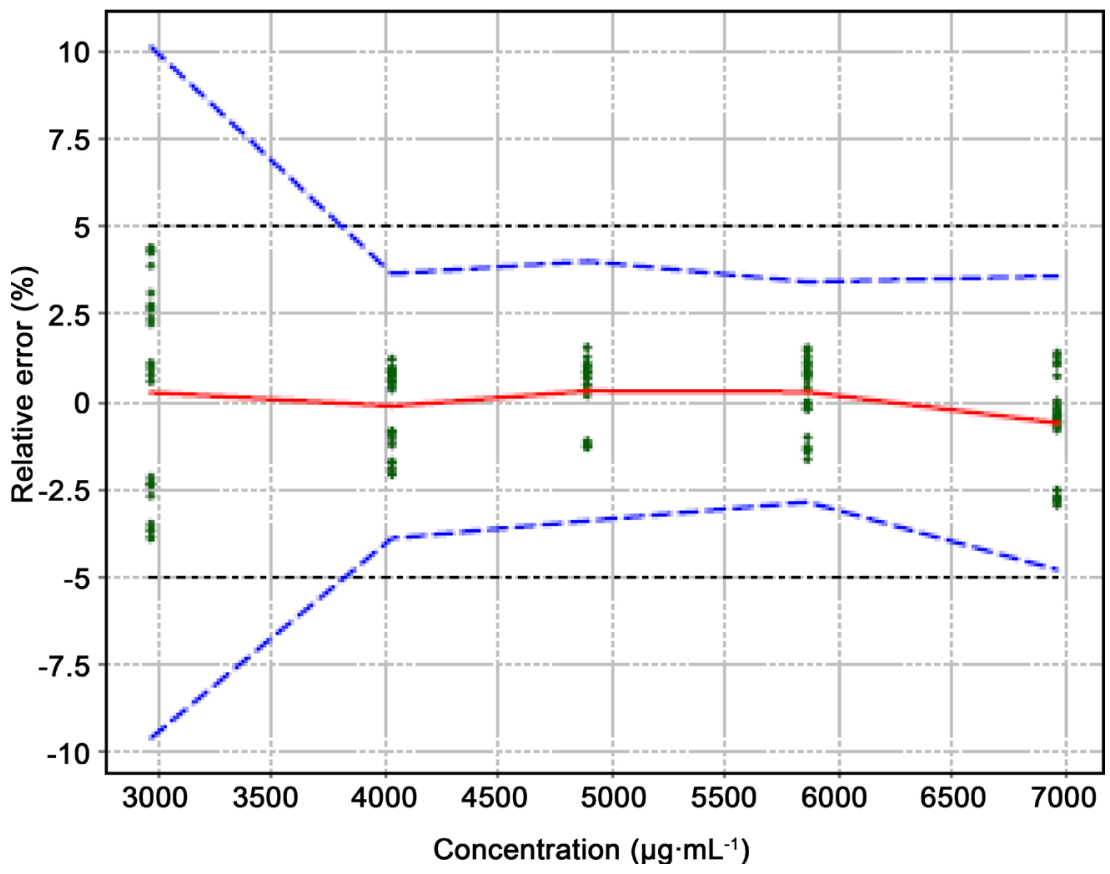

Figure 8. Accuracy profile for quantitative method validation of artesunate powder for injection. The plain red line represents the relative bias, the blue dashed lines the $95 \%$ $\beta$-expectation tolerance limits and the black dotted lines the $5 \%$ acceptance limits. The green dots express the relative error of the back-calculated concentrations plotted with respect to their targeted concentrations. (For interpretation of the references to color in this figure legend, the reader is referred to the web version of this article).

results of validation criteria summarized in Table 2. The acceptance limits were set at $\pm 5.0 \%$ according to the European Medicine Agency (EMA) standard for finished pharmaceutical products [23], and the analytical results from this method comply automatically with the larger specifications of $\pm 10.0 \%$ as per the International Pharmacopoeia monograph for artesunate powder for injection [24]. Indeed, we choose the narrower acceptable limits to allow the method being suitable to both regional requirements (European and International Pharmacopoeias), and the end-user regulatory authority shall choose which limit to enforce.

Then after, from the back-calculated results of VS that are the experimental ones, trueness of the method was assessed as it is the closeness of agreement between a conventionally accepted value (or reference value) that corresponds to the introduced concentrations of the analyte and a mean of experimental ones. We were able to get information on the systematic error that was found quite acceptable with relative biases between $-0.1 \%$ and $0.3 \%$ compared to the two considered acceptable limits.

The method precision was also found acceptable since there was a closeness of agreement among measurements; here, the back-calculated results of VS obtained from multiple sampling of homogeneous samples of the analyte. The relative standard deviation values for repeatability and for intermediate precision at the target of $100 \%$ concentration level were acceptable with a maximum of $0.3 \%$ 
Table 2. Summary of the validation criteria for artesunate powder for injection.

\begin{tabular}{|c|c|c|}
\hline Validation criteria & Conc. $\left(\mu \mathrm{g} \mathrm{mL} L^{-1}\right)$ & Artesunate \\
\hline \multirow{5}{*}{$\begin{array}{c}\text { Trueness: } \\
\text { Absolute bias }\left(\mu \mathrm{g} \mathrm{mL} L^{-1}\right) \\
(\text { Relative bias }(\%))\end{array}$} & 3000.0 & $7.9(0.3)$ \\
\hline & 4000.0 & $-4.8(-0.1)$ \\
\hline & 5000.0 & $15.0(0.3)$ \\
\hline & 6000.0 & $16.3(0.3)$ \\
\hline & 7000.0 & $-42.0(-0.6)$ \\
\hline \multirow{5}{*}{$\begin{array}{c}\text { Precision: } \\
\text { Repeatability (\%)/ } \\
\text { Intermediate precision (\%) }\end{array}$} & 3000.0 & $0.3 / 3.3$ \\
\hline & 4000.0 & $0.2 / 1.3$ \\
\hline & 5000.0 & $0.2 / 1.1$ \\
\hline & 6000.0 & $0.2 / 1.1$ \\
\hline & 7000.0 & $0.2 / 1.4$ \\
\hline \multirow{6}{*}{ 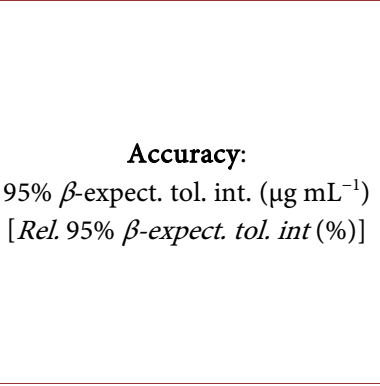 } & 3000.0 & $\begin{array}{c}2680-3264 \\
{[-9.593,10.13]}\end{array}$ \\
\hline & 4000.0 & $\begin{array}{l}3870-4174 \\
{[-3.9-3.7]}\end{array}$ \\
\hline & \multirow[b]{2}{*}{5000.0} & $4722-5084$ \\
\hline & & {$[-3.4-4.0]$} \\
\hline & 6000.0 & $\begin{array}{l}5692-6060 \\
{[-2.9-3.4]}\end{array}$ \\
\hline & 7000.0 & $\begin{array}{l}6628-7211 \\
{[-4.8-3.6]}\end{array}$ \\
\hline \multirow{3}{*}{ Linearity: } & Slope & 0.9916 \\
\hline & Intercept & 39.49 \\
\hline & $\mathrm{R}^{2}$ & 0.9975 \\
\hline \multirow{2}{*}{ Dosing range: } & Lower LOQ $\left(\mu \mathrm{g} \mathrm{mL} L^{-1}\right)$ & 3820 \\
\hline & Upper LOQ $\left(\mu g \mathrm{~mL}^{-1}\right)$ & 6962 \\
\hline
\end{tabular}

for repeatability, and 3.2\% for intermediate precision.

To demonstrate the method linearity, we assessed the relationship between the back-calculated results of VS (experimental ones) against the introduced concentrations. The linear regression model was fitted on the two types of concentrations, with a good linearity of the results illustrated in Table 2 by the slope close to 1 .

Moreover, method accuracy taking into account the total error, i.e. systematic and random errors, was assessed from the accuracy profile shown in Figure 8. In addition, as shown in Table 2 , the relative $\beta$-expectation tolerance intervals are within a range of $[-4.8 \%, 4.0 \%]$ except level 1 which is between $-9.6 \%$ and $10.1 \%$. Hence, as the lower and upper tolerance bounds are included within the acceptance limits for the targeted concentration level of $5000 \mu \mathrm{g} \mathrm{mL} \mathrm{m}^{-1}$, one can guarantee that at least $95 \%$ of future experimental results will fall within the acceptance limits [25].

We estimated also the limit of detection (LOD) that is the smallest quantity of the targeted substance that can be detected, but not accurately quantified in the 
sample. The computed value was $124.1 \mu \mathrm{g} \mathrm{mL} L^{-1}$.

The lower limit of quantitation (LLOQ) which is the smallest quantity of the targeted substance in the sample that can be assayed under experimental conditions with well-defined accuracy was calculated and its value is $3820 \mu \mathrm{g} \mathrm{m}^{-1}$ vs. the upper limit of quantitation (ULOQ) which is the highest quantity of the targeted substance in the sample that can be assayed under the experimental conditions with well-defined accuracy was calculated at $6962 \mu \mathrm{g} \mathrm{mL}{ }^{-1}$. In fact, those limits of quantitation were obtained by calculating the smallest and highest concentrations beyond which the accuracy limits or $\beta$-expectation limits go outside the acceptance limits. Hence, the intervals between the lower and the upper limits where the procedure achieves adequate accuracy allowed us to set the "Dosing range", again equivalent to [ $3820 \mu \mathrm{g} \mathrm{mL}^{-1}$ to $6962 \mu \mathrm{g} \mathrm{mL} \mathrm{m}^{-1}$ ].

Finally, the uncertainty which is a parameter associated with the result of a measurement that characterizes the dispersion of the values that could reasonably be attributed to the measurand was calculated, and its relative expanded value (\%) was found less than $3.1 \%$ on the four concentration levels except level 1.

\subsection{Application of the Methods}

The validated method for analysis of artesunate powder for injection was applied in the analysis of 3 different batches found in public hospitals in Rwanda during our sampling, whose results are presented in Table 3. The other methods were also applied in the analysis of artemether/lumefantrine in different samples of medicines sampled in the D.R. Congo (9 samples), Rwanda (13 samples) and Benin (1 suspected counterfeit) as reported in another article submitted to the Current Drug Safety Journal-Bentham Science Publishers [26], and the method for quinine and major cinchona alkaloids was used in the analysis of suspected counterfeit quinine tablets as reported in the American Journal of Analytical Chemistry [27].

The methods developed in Belgium on a LC Waters 2695 were successfully tested to Rwanda on two other LC systems namely Agilent 1200 series and Agilent 1260 series both equipped with diode array detector (DAD) from Agilent Technologies (Böblingen, Germany) and Chemetrix (Agilent Technologies authorized distributor, Midrand, South Africa) respectively (results not shown).

Table 3. Assay results of the analyzed three batch samples of artesunate powder for injection coded A, B and C sampled in Rwanda. The results consist in the mean percentage of claimed nominal content and the relative standard deviation calculated on 3 independent sample solutions per batch. Specifications are set to $90.0 \%-100.0 \%$ of the claimed nominal content $(\mathrm{mg})$.

\begin{tabular}{cccc}
\hline Drug sample & A & B & C \\
\hline Claimed & $60 \mathrm{mg}$ & $60 \mathrm{mg}$ & $60 \mathrm{mg}$ \\
Assay in \% & $99.4 \% \pm 0.5 \%$ & $99.4 \% \pm 0.1 \%$ & $100.4 \% \pm 0.4 \%$ \\
\hline
\end{tabular}




\section{Conclusions}

Simple isocratic methods were developed thanks to methods adaptation or adjustments approach, and sequential systematic tests without passing through long and expensive DoE. The isocratic methods were privileged for their simplicity, short analysis time and high sample throughput, low mobile phase consumption, and adaptability to LC systems equipped with simple or gradient pumps. In this regard, we developed a generic method for the analysis of: (i) artesunate, arteether and artemether in injectable forms; (ii) artemether and lumefantrine in tablets; and (iii) quinine-resorcin with major cinchona alkaloids (cinchonine, cinchonidine, quinidine, and dihydroquinine).

The analytical method for artesunate powder for injection derived from the generic method for artesunate, arteether and artemether was fully validated thanks to the strategy of total error and accuracy profile approach in accordance with the criteria of ICH Q2 (R1) guidelines; and finally, the methods were applied in the analysis of real samples of artemether/lumefantrine medicines, artesunate powder for injection, and counterfeit quinine tablets.

\section{Acknowledgements}

The Belgian Technical Cooperation (BTC/CTB) is acknowledged for scholarship and financial support to Védaste Habyalimana as well as the Belgian "Académie pour la Recherche et l'Enseignement Supérieur (ARES)” for supplementary funds to the scholarship of this author. Anonymous reviewers are also kindly acknowledged for their useful comments.

\section{References}

[1] World Health Organization (2017) Malaria, Fact Sheet Updated. http://www.who.int/mediacentre/factsheets/fs094/en/

[2] Choi, J. and Burke, D. (2017) Malaria. http://www.healthline.com/health/malaria\#overview1

[3] Newton, P.N., Amin, A.A., Bird, C., Passmore, P., Dukes, G., Tomson, G., Simons, B., Bate, R., Guerin, P.J. and White, N.J. (2012) The Primacy of Public Health Considerations in Defining Poor Quality Medicines. PLoS Medicine, 8, e1001139. https://doi.org/10.1371/journal.pmed.1001139

[4] Dégardin, K., Roggo, Y. and Margot, P. (2014) Understanding and Fighting the Medicine Counterfeit Market. Journal of Pharmaceutical and Biomedical Analysis, 87, 167-175. https://doi.org/10.1016/j.jpba.2013.01.009

[5] Kovacs, S., Hawes, S.E., Maley, S.N., Mosites, E., Wong, L. and Stergachis, A. (2014) Technologies for Detecting Falsified and Substandard Drugs in Low and Middle-Income Countries. PLOS ONE, 9, e90601. https://doi.org/10.1371/journal.pone.0090601

[6] Hansen, S.H., Pedersen-Bjergaard, S. and Rasmussen, K.E. (2012) Introduction to Pharmaceutical Chemical Analysis, Chapter 13: High Performance Liquid Chromatography. John Wiley \& Sons Publication, New York, 174-175

[7] ICH Harmonised Tripartite Guideline: Validation of Analytical Procedures: Text and Methodology Q2 (R1) (2005). 
https://www.ich.org/fileadmin/Public_Web_Site/ICH_Products/Guidelines/Quality /Q2_R1/Step4/Q2_R1__Guideline.pdf

[8] Hubert, Ph., Nguyen-Huu, J.-J., Boulanger, B., Chapuzet, E., Chiap, P., Cohen, N., Compagnon, P.-A., Dewé, W., Feinberg, M., Lallier, M., Laurentie, M., Mercier, N., Muzard, G., Nivet, C. and Valat, L. (2004) Harmonization of Strategies for the Validation of Quantitative Analytical Procedures: A SFSTP Proposal-Part I. Journal of Pharmaceutical and Biomedical Analysis, 36, 579-586.

[9] Hubert, Ph., Nguyen-Huu, J.-J., Boulanger, B., Chapuzet, E., Chiap, P., Cohen, N., Compagnon, P.-A., Dewé, W., Feinberg, M., Lallier, M., Laurentie, M., Mercier, N., Muzard, G., Nivet, C., Valat, L. and Rozet, E. (2007) Harmonization of Strategies for the Validation of Quantitative Analytical Procedures: A SFSTP Proposal-Part II. Journal of Pharmaceutical and Biomedical Analysis, 45, 70-81. https://doi.org/10.1016/j.jpba.2007.06.013

[10] Hubert, Ph., Nguyen-Huu, J.-J., Boulanger, B., Chapuzet, E., Cohen, N., Compagnon, P.-A., Dewé, W., Feinberg, M., Laurentie, M., Mercier, N., Muzard, G., Valat, L. and Rozet, E. (2007) Harmonization of Strategies for the Validation of Quantitative Analytical Procedures: ASFSTP Proposal-Part III. Journal of Pharmaceutical and Biomedical Analysis, 45, 82-96. https://doi.org/10.1016/j.jpba.2007.06.032

[11] Hubert, Ph., Nguyen-Huu, J.-J., Boulanger, B., Chapuzet, E., Cohen, N., Compagnon, P.-A., Dewé, W., Feinberg, M., Laurentie, M., Mercier, N., Muzard, G., Valat, L. and Rozet, E. (2008) Harmonization of Strategies for the Validation of Quantitative Analytical Procedures: A SFSTP Proposal: Part IV-Examples of Application. Journal of Pharmaceutical and Biomedical Analysis, 48, 760-771. https://doi.org/10.1016/j.jpba.2008.07.018

[12] Guillarme, D., Nguyen, D., Rudaz, S. and Veuthey, J.-L. (2008) HPLC Calculator v3.0: Software for Chromatographic Performance Evaluation and HPLC Method Transfer. European Journal of Pharmaceutics and Biopharmaceutics, 68, 430-440. https://doi.org/10.1016/j.ejpb.2007.06.018

[13] The United States Pharmacopeial Convention, USP39-NF34 (2016) General Chapters: $<621>$ Chromatography—System Suitability.

[14] European Pharmacopoeia (2015) Methods of Analysis-Chromatographic Separation Techniques-Adjustment of Chromatographic Conditions. 8th Edition.

[15] The International Pharmacopoeia (2016) High-Performance Liquid Chromatography-System Suitability-Adjustment of Chromatographic Conditions. 6th Edition. http://apps.who.int/phint/pdf/b/Jb.7.1.14.4.pdf

[16] Mbinze, J.K., Loconon, A.Y., Lebrun, P., Sacré, P.-Y., Habyalimana, V., Kalenda, N., Bigot, A., Atindehou, E., Hubert, Ph. and Marini, R.D. (2015) Fighting Poor Quality Medicines: Development, Transfer and Validation of Generic HPLC Methods for Analyzing Two WHO Recommended Antimalarial Tablets. American Journal of Analytical Chemistry, 6, 127-144. https://doi.org/10.4236/ajac.2015.62012

[17] International Pharmacopoeia (2016) Quinine Bisulfate Tablets; Quinine Dihydrochloride Injection; Quinine Sulfate Tablets; Quinine Bisulfate; Quinine Dihydrochloride; Quinine Hydrochloride; Quinine Sulfate. 6th Edition. http://apps.who.int/phint/en/p/docf/

[18] YMC Co. Ltd. (Japan) (n.d.) Columns-YMC-Pack Pro C8\&C4-Separation of Basic Compounds. http://www.ymc.co.jp/en/columns/ymc_pack_pro_c8_c4/

[19] McCalley, D.V. (1986) Analysis of the Cinchona Alkaloids by High-Performance Liquid Chromatography: Use as Probes of Activity towards Basic Compounds Shown by Reversed-Phase Columns. Journal of Chromatography A, 357, 221-226. 
https://doi.org/10.1016/S0021-9673(01)95824-8

[20] Republic of Rwanda, Ministry of Health (2010) National List of Essential Medicines, 5th Edition. http://apps.who.int/medicinedocs/documents/s17569fr/s17569fr.pdf

[21] Republic of Rwanda, Ministry of Health (2015) National List of Essential Medicines for Adults. 6th Edition.

http://moh.gov.rw/fileadmin/templates/Docs/NEML_For_Adults_6th_Edition_201 5.pdf

[22] Republic of Rwanda, Ministry of Health (2015) National List of Essential Medicines for Paediatrics.

http://moh.gov.rw/fileadmin/templates/Docs/NEML_For_Paediatrics-_1st_Edition2015.pdf

[23] European Medicines Agency (EMA) (1991) Specifications and Control Tests on the Finished Product. Directive 75/318/EEC.

http://www.ema.europa.eu/docs/en_GB/document_library/Scientific_guideline/200 9/09/WC500003368.pdf

[24] International Pharmacopoeia (2016) Artesunate for Injection. 6th Edition. http://apps.who.int/phint/pdf/b/Jb.6.2.2.20.pdf

[25] Commission SFSTP, Hubert, Ph., Nguyen-Huu, J.J., Boulanger, B., Chapuzet, E., Chiap, P., Cohen, N., Compagnon, P.A., Dewe, W., Feinberg, M., Lallier, M., Laurentie, M., Mercier, N., Muzard, G., Nivet, C. and Valat, L. (2003) Validation des procédures analytiques quantitatives Harmonisation des demarches. [Validation of Quantitative Analytical Procedure, Harmonization of Approaches.] STP Pharma Pratiques, 13, 101-138. http://hdl.handle.net/2268/22157

[26] Yemoa, A., Habyalimana, V., Mbinze, J.K., Crickboom, V., Muhigirwa, B., Ngoya, A., Sacré, P.-Y., Gbaguidi, F., Quetin-Leclercq, J., Hubert, Ph. and Marini, R.D. (2017) Detection of Poor Quality Artemisinin-Based Combination Therapy (ACT) Medicines Marketed in Benin Using Simple and Advanced Analytical Techniques. Current Drug Safety Journal, 12, E-Pub Abstract Ahead of Print.

[27] Habyalimana, V., Mbinze, J.K., Tshilombo, N.K., Dispas, A., Loconon, A.Y., Sacré, P.-Y., Widart, J., De Tullio, P., Counerotte, S., Ntokamunda, J.-L.K., Ziemons, E., Hubert, Ph. and Djang'eing'a, R.M. (2015) Analytical Tools and Strategic Approach to Detect Poor Quality Medicines, Identify Unknown Components, and Timely Alerts for Appropriate Measures: Case Study of Antimalarial Medicines. American Journal of Analytical Chemistry, 6, 977-994. 
Submit or recommend next manuscript to SCIRP and we will provide best service for you:

Accepting pre-submission inquiries through Email, Facebook, LinkedIn, Twitter, etc. A wide selection of journals (inclusive of 9 subjects, more than 200 journals)

Providing 24-hour high-quality service

User-friendly online submission system

Fair and swift peer-review system

Efficient typesetting and proofreading procedure

Display of the result of downloads and visits, as well as the number of cited articles Maximum dissemination of your research work

Submit your manuscript at: http://papersubmission.scirp.org/

Or contact ajac@scirp.org 